\title{
ENRAIZAMENTO DE ESTACAS DE Jasminum polyanthum TRATADAS COM ÁCIDO INDOLBUTÍRICO
}

\section{ROOTING OF Jasminum polyanthum CUTTINGS TREATED WITH INDOLEBUTYRIC ACID}

\author{
Sibelle Santanna da SILVA ${ }^{1}$ \\ Ana Cláudia KLOSOWSKI ${ }^{1}$ \\ Renata KOYAMA ${ }^{2}$ \\ Cássio Angelo FABRI ${ }^{2}$ \\ Leonardo Luiz GOMES ${ }^{2}$ \\ Katia Christina ZUFFELLATO-RIBAS ${ }^{3}$
}

\section{RESUMO}

Jasmim dos poetas (Jasminum polyanthum) é uma espécie ornamental muito utilizada no paisagismo. Porém, poucas pesquisas têm sido desenvolvidas sobre a eficiência de sua propagação vegetativa. Este trabalho teve como objetivo avaliar o enraizamento de estacas caulinares com $8 \mathrm{~cm}$ de comprimento de Jasminum polyanthum, tratadas com diferentes concentrações de ácido indolbutírico (IBA) veiculadas em talco e em solução hidroalcoólica, nas concentrações de 0,1000 , 1500 e $3000 \mathrm{mg} \mathrm{L}^{-1}$ ou mg Kg${ }^{-1}$ de IBA. Após os tratamentos, as estacas foram plantadas em tubetes contendo vermiculita de granulometria média e mantidas em casa de vegetação com nebulização intermitente por 54 dias. As variáveis analisadas foram: porcentagem de estacas enraizadas, número de raízes formadas por estaca, comprimento de raízes formadas por estaca, porcentagem de estacas com calos, porcentagem de estacas vivas e porcentagem de estacas mortas. Não houve diferença significativa entre os diversos tratamentos para as variáveis estacas com calos, comprimento de raízes e número de raízes por estaca. Com relação ao enraizamento, a ausência da aplicação de IBA em solução ou talco (testemunha) apresentou resultados satisfatórios na porcentagem de estacas enraizadas $(80 \%)$, comprimento de raízes $(3,46$ e $3,66 \mathrm{~cm}$ respectivamente) e número de raízes por estaca (5,55 e 4,95 respectivamente), sendo dispensável a aplicação de IBA para promover o enraizamento nesta espécie.

Palavras-chave: Jasmim dos poetas, estaquia, regulador vegetal, auxina.

\section{ABSTRACT}

Poet's jasmine (Jasminum polyanthum) is a species widely used is ornamental landscaping. But little research was been done on the efficiency of propagaton of this species. This study aimed to evaluate the rooting of stem, $8 \mathrm{~cm}$ in length Jasminum polyanthum treated with different concentrations of butyric acid (IBA) by the powder and water-alcohol solution at concentrations of $0,1000,1500$ and $3000 \mathrm{mg} \mathrm{L}-1$ or mg kg-1 of IBA. After the treatments, the cuttings were planted in tubes containing vermiculite and maintained an average particle size in a greenhouse with intermittent mist for 54 days. The variables were: rooting percentage, number of roots per cutting, root length per cutting, percentage of cuttings with callus, percentage of live cuttings and percentage of dead cuttings. Significant difference was not found between treatments for the variables cuttings with callus, root length and root number per cutting. In relation to rooting, the absense of application of IBA in talc or solution (control) showed satisfactory results in rooting percentage $(80 \%)$, root length $(3.46$ and $3.66 \mathrm{~cm}$ respectively) and number of roots per cuttings (5.55 and 4.95 respectively), being dispensable the application of IBA to promote rooting in this species.

Key words: Jasminum polyanthum, rooting, plant growth regulators, IBA.

\footnotetext{
${ }^{1} \mathrm{Eng}^{\circ}$ Agrônoma, Mestranda em Agronomia - Produção Vegetal, Departamento de Fitotecnia e Fitossanitarismo, Universidade Federal do Paraná; Curitiba-PR. E-mail: sibelless@gmail.com; annackl@hotmail.com ${ }^{2} \mathrm{Enn}^{\circ}$ Agrônomo, Universidade Federal do Paraná; Curitiba-PR. E-mail: emykoyama@hotmail.com; poderdaflor@yahoo.com.br; leoluizgomes@yahoo.com.br
}

${ }^{3}$ Professora Pós-Doutora, Departamento de Botânica, Universidade Federal do Paraná (UFPR), Centro Politécnico - Jardim das Américas, CP: 19031, CEP: 81531-970, Curitiba - PR. E-mail: kazu@ufpr.br 
SILVA, S.S., et al. Enraizamento de estacas...

\section{INTRODUÇÃO}

Jasminum polyanthum, conhecido popularmente como jasmim dos poetas, é uma trepadeira semi-herbácea da Família Oleaceae, originária da China, de crescimento moderado, ramificado, de ramagem e florescimento decorativo. Possui folhas compostas com 5 - 7 folíolos lanceolados, sobre ramos de coloração avermelhada (Souza \& Lorenzi, 2005).

De acordo com Ehlert et al. (2004) uma importante forma de propagação de espécies lenhosas e herbáceas é a propagação vegetativa, sendo esta muito utilizada em espécies de relevância econômica e ornamental. Há várias técnicas para se fazer a propagação vegetativa, e para cada espécie deve-se saber qual é a mais adequada.

A estaquia é um dos principais métodos de propagação vegetativa, onde se utilizam segmentos destacados da planta mãe (Norberto et al., 2001), que possuam pelo menos uma gema vegetativa com capacidade para originar um novo indivíduo, podendo ser estes oriundos de caule, folha ou raiz, os quais regeneram as partes faltantes (Gomes et al., 2002; Bortolini et al., 2008). O uso desse método de propagação permite a obtenção de clones, que são grupos de plantas provenientes de uma matriz em comum, ou seja, com material genético uniforme e com idênticas necessidades climáticas, edáficas, nutricionais e de manejo (Rossal, 2006).

Para espécies que podem ser propagadas vegetativamente, a estaquia apresenta inúmeras vantagens (Wassner \& Ravetta, 2000); além de permitir que as características de interesse sejam mantidas, ela pode aumentar consideravelmente a qualidade dos plantios florestais e ornamentais (Mckeand et al., 2006). O sucesso no plantio de mudas clonais está ligado ao desenvolvimento radicial das estacas, e, portanto, é necessário observar não somente o percentual de enraizamento, mas também o número e o comprimento destas raízes (Rocha Correa \& Fett-Neto, 2004).

Segundo Pasqual et al. (2001), é necessário que haja um balanço hormonal entre promotores e inibidores do processo de iniciação radicial. A maneira mais comum de promover esse equilíbrio é pela aplicação exógena de reguladores vegetais, como o ácido indolbutírico (IBA), que podem elevar a concentração de auxina no tecido (Hinojosa, 2000).

O efeito benéfico das auxinas exógenas varia de acordo com a espécie, com as cultivares e também com as diferentes concentrações utilizadas (Colombo et al., 2008). A aplicação de auxina na base das estacas pode ser feita por meio de diferentes veículos, destacando-se a forma líquida e em talco. A aplicação em talco é muito utilizada por ser de fácil manuseio e geralmente proporciona bons resultados. Porém o talco pode ser lixiviado com o tempo, e por não possuir uma aplicação homogênea, pode ocasionar um enraizamento desuniforme em todo o diâmetro da estaca (Fortes, 1998). Segundo Hartmann et al. (2002), a aplicação de IBA pela via líquida, em solução hidroalcoólica, é mais efetiva que a aplicação em talco, pois apresenta resultados mais uniformes.

Assim, devido à escassez de estudos que envolvam o enraizamento de estacas caulinares de jasmim dos poetas, realizou-se este trabalho com o objetivo de avaliar os efeitos da aplicação de diferentes concentrações do ácido indolbutírico (IBA) em talco e em solução hidroalcoólica, na indução do enraizamento desta espécie.

\section{MATERIAL E MÉTODOS}

O experimento foi realizado no Laboratório de Macropropagação do Departamento de Botânica, no Setor de Ciências Biológicas, da Universidade Federal do Paraná (UFPR), em Curitiba - PR, entre os meses de agosto e outubro de 2010.

Foram utilizados ramos semi-herbáceos de Jasminum polyanthum (jasmim dos poetas), retirados de uma planta adulta com 9 anos de idade, medindo 2,5 metros de altura, localizada em jardins do bairro Juvevê, em Curitiba - PR.

O material vegetal foi coletado quatro horas antes da implantação do experimento e acondicionado em baldes com água para evitar ressecamento, sendo transportado em sacos plásticos umedecidos até a UFPR.

Utilizando-se tesoura de poda foram confeccionadas estacas com comprimento aproximado de $8 \mathrm{~cm}$ e aproximadamente $2 \mathrm{~mm}$ de diâmetro, com corte reto na porção apical e em bisel na base, mantendo-se 4 folíolos no ápice.

As estacas foram submetidas a tratamento fitossanitário em solução de hipoclorito de sódio a $0,5 \%$ por 10 minutos, sendo posteriormente lavadas em água corrente por 5 minutos. As bases das estacas foram tratadas com soluções hidroalcoólicas $(50 \%)$ de ácido indolbutírico (IBA) nas seguintes concentrações: 0, 1000, 1500 e $3000 \mathrm{mg} \mathrm{L}^{-1}$ de IBA, por 10 segundos e as mesmas concentrações diretamente no pó, quando veiculadas sob a forma de talco. Os tratamentos controle possuíam solução hidroalcoólica a $50 \%$ ou talco inerte. O plantio foi realizado no dia 25 de agosto de 2010, em tubetes de $53 \mathrm{~cm}^{3}$ contendo vermiculita de granulometria média, permanecendo em casa de vegetação por 54 dias, com nebulização intermitente, com $24^{ \pm} 2^{\circ} \mathrm{C}$ e UR de $90 \%$

Aos 54 dias após a instalação do experimento, foram avaliadas a porcentagem de estacas enraizadas (estacas vivas que emitiram raiz maior que $1 \mathrm{~mm}$ ), o número de raízes formadas por estacas, o comprimento das três maiores raízes formadas por estaca $(\mathrm{cm})$, a porcentagem de estacas com calos (estacas vivas, sem raiz e com a presença de calos na base), a porcentagem de estacas vivas (estacas vivas, sem raízes e sem calos) e a porcentagem de estacas mortas (estacas com tecido necrosado).

$O$ experimento foi montado num esquema fatorial de $4 \times 2$ (4 concentrações $\times 2$ formas de aplicação), com 4 repetições, contendo 10 estacas por repetição, totalizando 40 estacas por tratamento, num total de 320 estacas. Para testar a homogeneidade dos tratamentos se utilizou o teste Bartlett. Os dados foram submetidos à análise de variância 
pelo teste $\mathrm{F}$ e as médias comparadas pelo teste Tukey a $5 \%$ de probabilidade. Os dados originais das variáveis em porcentagem foram transformados para arco-seno raiz de $\mathrm{x} / 100$.

\section{RESULTADOS E DISCUSSÃO}

$\mathrm{Na}$ Tabela 1 observa-se que somente as variáveis estacas enraizadas (ER) e estacas vivas (EV) apresentaram efeito significativo dos tratamentos utilizados, sendo a maior porcentagem de enraizamento $(85 \%)$ verificada nos tratamentos $1000 \mathrm{e}$ $1500 \mathrm{mg} \mathrm{L}^{-1}$ de IBA e $3000 \mathrm{mg} \mathrm{Kg}^{-1}$ de IBA (75\%).

TABELA 1 - Porcentagem de estacas de jasmim dos poetas (Jasminum polyanthum) enraizadas (EE), número de raízes por estaca (NRE), comprimento de raízes por estaca (CR), porcentagem de estacas com calos (EC), vivas (EV) e mortas (EM), submetidas a diferentes concentrações de AlB veiculadas em solução hidroalcoólica e em talco.

\begin{tabular}{|c|c|c|c|c|c|c|c|c|c|c|c|c|}
\hline \multirow{3}{*}{ 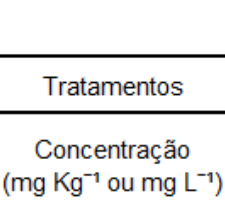 } & \multicolumn{12}{|c|}{ Variáveis } \\
\hline & \multicolumn{2}{|c|}{ EE (\%) } & \multicolumn{2}{|c|}{ NRE } & \multicolumn{2}{|c|}{$\mathrm{CR}(\mathrm{cm})$} & \multicolumn{2}{|c|}{ EC (\%) } & \multicolumn{2}{|c|}{ EV (\%) } & \multicolumn{2}{|c|}{ EM (\%) } \\
\hline & Solução & Talco & Solução & Talco & Solução & Talco & Solução & Talco & Solução & Talco & Solução & Talco \\
\hline 0 & $80,00 \mathrm{Aa}$ & $80,00 \mathrm{Aa}$ & 5,55 & 4,95 & 3,46 & 3,66 & 15,00 & 12,50 & $5,00 \mathrm{Ba}$ & $7,50 \mathrm{Ba}$ & 0,00 & 0,00 \\
\hline 1000 & $85,00 \mathrm{Aa}$ & $67,50 \mathrm{Ba}$ & 5,13 & 4,35 & 3,64 & 3,97 & 12,50 & 20,00 & $2,50 \mathrm{Ba}$ & $12,50 \mathrm{Aa}$ & 0,00 & 0,00 \\
\hline 1500 & $85,00 \mathrm{Aa}$ & $80,00 \mathrm{Aa}$ & 5,13 & 5,08 & 3,67 & 4,07 & 12,50 & 15,00 & $2,50 \mathrm{Ba}$ & $5,00 \mathrm{Ba}$ & 0,00 & 0,00 \\
\hline 3000 & $71,00 \mathrm{Aa}$ & $85,00 \mathrm{Aa}$ & 4,25 & 5,58 & 3,05 & 4,10 & 13,25 & 12,50 & $12,75 \mathrm{Aa}$ & $2,50 \mathrm{Ba}$ & 2,75 & 0,00 \\
\hline CV (\%) & \multicolumn{2}{|c|}{49,26} & \multicolumn{2}{|c|}{10,93} & \multicolumn{2}{|c|}{8,69} & \multicolumn{2}{|c|}{4,74} & \multicolumn{2}{|c|}{11,72} & \multicolumn{2}{|c|}{0,00} \\
\hline F teste & \multicolumn{2}{|c|}{3,19} & \multicolumn{2}{|c|}{-} & \multicolumn{2}{|c|}{-} & \multicolumn{2}{|c|}{ 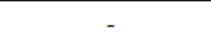 } & \multicolumn{2}{|c|}{3,24} & \multicolumn{2}{|c|}{-} \\
\hline
\end{tabular}

*Médias com letras maiúsculas distintas nas colunas e minúsculas nas linhas, para cada variável analisada, diferem entre si pelo teste de Tukey $(p<0,05)$.

$\mathrm{Na}$ avaliação do percentual de estacas enraizadas, não houve diferença significativa entre as formas de aplicação. Verificou-se que a aplicação do regulador via talco mostrou uma queda no percentual de enraizamento de estacas na concentração de $1000 \mathrm{mg} \mathrm{L}^{-1}$ de IBA, correspondendo a $67,5 \%$ de estacas enraizadas. A porcentagem de enraizamento obtida nos tratamentos que continham maiores concentrações de IBA via talco foi satisfatória, chegando a $85 \%$. No entanto esse índice não difere estatisticamente do obtido com a testemunha, não sendo necessária a aplicação de IBA via talco para aprimorar o enraizamento.

$\mathrm{Na}$ aplicação em solução, apesar de não haver diferenças estatísticas, conforme os resultados observados, a maior dose de IBA, $3000 \mathrm{mg} \mathrm{Kg}^{-1}$ resultou numa menor taxa de estacas enraizadas, com uma porcentagem de $71 \%$ de enraizamento. Observa-se ainda na Tabela 1 que os resultados obtidos com a aplicação de IBA em concentrações de 1000 e $1500 \mathrm{mg} \mathrm{L}^{-1}$ chegaram a um índice de $85 \%$ de enraizamento, sendo que este resultado não diferiu do percentual de estacas enraizadas obtido no tratamento testemunha, sem aplicação de IBA (Tabela 1), tornando-se também dispensável a aplicação de IBA em solução hidroalcoólica.

Segundo Hartmann et al. (2002) há a hipótese de que as espécies que possuem facilidade de formarem raízes adventícias apresentem equilíbrio entre promotores e inibidores do processo de iniciação radicial, ou seja, um balanço endógeno adequado, e uma simples injúria provocada por um corte na base da estaca, durante o seu preparo, já ative todo o mecanismo de ação das substâncias que induz à formação de raízes. Desta forma, Jasminum polyanthum apresenta um balanço endógeno adequado, pois obteve aos 54 dias, $85 \%$ das estacas enraizadas.

Na propagação vegetativa de plantas, existe uma interação entre auxinas e citocininas. A alta interação auxina/citocinina favorece o enraizamento. Já a alta relação citocinina/auxina favorece a formação de brotações. Quando existe um alto nível de ambos hormônios, a formação de calos é favorecida (Hartmann et al., 2002).

Não houve diferença entre os tratamentos quanto à formação de calos, e a porcentagem média de estacas com calos foi de $14 \%$. É interessante que este índice seja baixo, podendo-se refletir em maior porcentagem de estacas que formam raízes.

A aplicação do regulador vegetal nas concentrações de $1000 \mathrm{mg} \mathrm{Kg}^{-1}$ de IBA em talco e 3000 $\mathrm{mg} \mathrm{L}^{-1}$ em solução hidroalcoólica, resultaram em uma porcentagem maior de estacas vivas. Deve-se lembrar conceitualmente que estacas vivas, no presente trabalho, se refere àquelas estacas que não morreram e nem formaram calos, porém também não formaram raízes. Portanto, uma maior porcentagem de estacas vivas não pode estar relacionada com uma menor porcentagem de mortalidade (Tabela 1).

No comprimento das raízes por estaca não houve diferença estatística entre os resultados. Analisando-se os valores absolutos, aqueles obti- 
dos pela aplicação das diferentes concentrações via solução hidroalcoólica, os resultados apontaram valores inferiores ao da testemunha, e quanto maior a concentração, maior o efeito negativo sobre o comprimento das estacas. Contudo, as médias dos tratamentos usando o talco como veículo mostraram que as aplicações em maiores concentrações obtiveram raízes com maior comprimento. No experimento realizado por Yamamoto et al. (2010), com Psidium guajava $L$. tratadas com IBA, foi verificado que as maiores concentrações do regulador vegetal tanto em álcool quanto em talco provocaram maiores comprimentos de raízes.
Em relação ao número de estacas mortas, também não houve significância, sendo que foi observada apenas 1 (uma) estaca morta dentre todas as estacas avaliadas no experimento.

\section{CONCLUSÃO}

Não há necessidade da aplicação de IBA para incrementar o enraizamento de Jasminum polyanthum, uma vez que a testemunha $\left(0 \mathrm{mg} \mathrm{L}^{-1}\right.$ de IBA) apresentou resultados satisfatórios na porcentagem de estacas enraizadas, comprimento de raízes e número de raízes por estaca.

\section{REFERÊNCIAS}

1. BORTOLINI, M.F.D.M. de; ALCANTARA, G.B. de; FANTI, F.P.; BIASI, L.A.; QUOIRIN, M. KOEHLER, H.S.; ZUFFELLATO-RIBAS, K.C. Enraizamento de estacas de Ficus benjamina L. Scientia Agraria, v. 9, n. 4, p. 539-543, 2008

2. COLOMBO, L.A.; TAZIMA, Z. H.; MAZZINI, R. B.; ANDRADE, G. A.; KANAYAMA, F. S.; BAQUERO, J. E.; AULER, P A. M.; ROBERTO, S. R. Enraizamento de estacas herbáceas da seleção 8501-1 de goiabeira submetidas à lesão na base e a concentrações de AIB. Semina: Ciências Agrárias, v. 29, n. 3, p. 539-546, 2008.

3. EHLERT, P. A. D.; LUZ J. M. Q.; INNECO R. Propagação vegetativa de alfavaca-cravo utilizando diferentes tipos de estacas e substratos. Horticultura Brasileira, v.22, n.1, p.10-13, 2004.

4. FORTES, A.M.T. Efeito de auxinas e ácido bórico em dois métodos de aplicação no enraizamento de estacas de rosa. Dissertação (Mestrado em Ciências Biológicas) - Universidade Estadual Paulista Julio de Mesquita, Botucatu, 1998, 95p.

5. GOMES, G.A.C.; PAIVA, R.; SANTANA, J.R.F. de; PAIVA, P.D. de O.; CHALFUN, N.N.J. Propagação de espécies lenhosas. Informe Agropecuário, v. 23, n. 216, p.12-15, 2002

6. HARTMANN, H.T.; KESTER, D.E.; DAVES, F.; GENEVE, F. Plant propagation: principles and practices. 7 ed. New Jersey: Prentice-Hall, 2002, $880 \mathrm{p}$

7. HINOJOSA, G.F. Auxinas. In: CID, L.P.B. Introdução aos hormônios vegetais. Brasília, DF: Embrapa, p. 15-54, 2000.

8. MCKEAND, S.E.; JOKELA, E. J.; HUBER, D. A.; BYRAM, T. D.; LEE ALLEN, H.; LLI, B.; MULLIN, T. J. Performance of improved genotypes of loblolly pine across different soils, climates, and silvicultural inputs. Forest Ecology and Management, v. 227, p.178-184, 2006

9. NORBERTO, P.M.; CHALFUN, N.N.J.; PASQUAL, M.; VEIGA, R.D.; PEREIRA, G.E.; MOTA, J.H. Efeito da época de estaquia e do AIB no enraizamento de estacas de figueira (Fícus carica L.). Ciência e Agrotecnologia. v. 25, n. 3, p. 533-541, 2001.

10. PASQUAL, M.; CHALFUN, N.N.J.; RAMOS, J.D.; VALE, M.R. do; SILVA, C.R. de. Fruticultura comercial: propagação de plantas frutíferas. Lavras: UFLA/FAEPE, 2001, $137 \mathrm{p}$

11. ROCHA CORREA, L.D.; FETT-NETO, A.G. Effects of temperature on adventitious root development in microcuttings of Eucalyptus saligna Smith and Eucalyptus globulus Labill. Journal of Thermal Biology, v. 29, p. 315-324, 2004.

12. ROSSAL, P.A.L. Qualidade da luz e ácido 4-(3-indolil) butírico na formação de raízes adventícias em estacas caulinares. Tese (Doutorado em Agronomia Área de concentração: Fitotecnia) - Universidade de São Paulo Escola Superior de Agricultura "Luiz de Queiroz" Piracicaba, 2006, 76 p.

13. SOUZA, V.C.; LORENZI, H. Botânica sistemática: um guia ilustrado para identificação das famílias de Angiospermas da flora brasileira, baseado em APG II. Nova Odessa: Instituto Plantarum, 2005. 640 p.

14. WASSNER, D.; RAVETTA, D. Vegetative propagation of Grindelia chiloensis (Asteraceae). Industrial Crops and Products, v. 11, p. 7-10, 2000.

15. YAMAMOTO, L. Y.; BORGES, R. S.; SORACE, M.; RACHID, B, F.; RUAS, J. M. F.; SATO, O.; ASSIS, A . M.; ROBERTO, S. R. Enraizamento de estacas de Psidium guajava L. 'Século XXI' tratadas com ácido indolbutírico veiculado em talco e álcool. Ciência Rural, v. 40, n. 5, p. 1037-1042, 2010. 